Louisiana State University

LSU Digital Commons

Faculty Publications

Department of Biological Sciences

$12-24-2004$

\title{
Toward a systems approach to understanding plant cell walls
}

\author{
Chris Somerville \\ Carnegie Institution of Washington \\ Stefan Bauer \\ Carnegie Institution of Washington \\ Ginger Brininstool \\ Carnegie Institution of Washington \\ Michelle Facette \\ Carnegie Institution of Washington \\ Thorsten Hamann \\ Carnegie Institution of Washington
}

See next page for additional authors

Follow this and additional works at: https://digitalcommons.Isu.edu/biosci_pubs

\section{Recommended Citation}

Somerville, C., Bauer, S., Brininstool, G., Facette, M., Hamann, T., Milne, J., Osborne, E., Paredez, A., Persson, S., Raab, T., Vorwerk, S., \& Youngs, H. (2004). Toward a systems approach to understanding plant cell walls. Science, 306 (5705), 2206-2211. https://doi.org/10.1126/science.1102765

This Article is brought to you for free and open access by the Department of Biological Sciences at LSU Digital Commons. It has been accepted for inclusion in Faculty Publications by an authorized administrator of LSU Digital Commons. For more information, please contact ir@lsu.edu. 


\section{Authors}

Chris Somerville, Stefan Bauer, Ginger Brininstool, Michelle Facette, Thorsten Hamann, Jennifer Milne, Erin Osborne, Alex Paredez, Staffan Persson, Ted Raab, Sonja Vorwerk, and Heather Youngs 


\title{
Toward a Systems Approach to Understanding Plant Cell Walls
}

\author{
Chris Somerville, ${ }^{1,2 *}$ Stefan Bauer, ${ }^{1}$ Ginger Brininstool, ${ }^{1}$ Michelle Facette, ${ }^{1,2}$ Thorsten Hamann, ${ }^{1}$ Jennifer Milne, ${ }^{1}$ \\ Erin Osborne, ${ }^{1}$ Alex Paredez, ${ }^{1,2}$ Staffan Persson, ${ }^{1}$ Ted Raab, ${ }^{1}$ Sonja Vorwerk, ${ }^{1}$ Heather Youngs $^{1,2}$
}

One of the defining features of plants is a body plan based on the physical properties of cell walls. Structural analyses of the polysaccharide components, combined with highresolution imaging, have provided the basis for much of the current understanding of cell walls. The application of genetic methods has begun to provide new insights into how walls are made, how they are controlled, and how they function. However, progress in integrating biophysical, developmental, and genetic information into a useful model will require a system-based approach.

$\mathbf{P}$ lant cell walls are complex and dynamic structures composed mostly of polysaccharides with high molecular weights (1-4), highly glycosylated proteins, and lignin. As a measure of the complexity, the Arabidopsis genome contains more than 730 genes encoding putative glycosyltransferases or glycosyl hydrolases (5) and several hundred additional genes encoding other types of proteins implicated in wall biosynthesis or function. Although their general catalytic activity can often be inferred from sequence, the precise enzymatic function and biological role of most of these proteins are unknown (2). For example, genetic analysis has identified the specific biological role for only two of the more than 170 gene products with similarity to pectin-degrading enzymes $(6,7)$.

Faced with the prospect of analyzing the function of 1000 or more genes that may contribute to the synthesis and remodeling of cell walls, we explored the idea that a systems approach may provide a useful framework for defining the hierarchy of essential questions. The concept of systems biology has recently emerged as a way of envisioning how multifactorial biological processes operate as a whole (8). The concept is usually applied to understanding networks of genes or gene products but is more broadly applicable. Kitano (8) defines four key elements in a system: the design principles, system structure, the control method, and the system dynamics. Here, we attempted to evaluate the current state of knowledge about the poly-

${ }^{1}$ Carnegie Institution, Department of Plant Biology, 260 Panama Street, Stanford, CA 94305, USA. ${ }^{2}$ Department of Biological Sciences, Stanford University, Stanford, CA 94305, USA.

*To whom correspondence should be addressed. E-mail: crs@stanford.edu saccharide components of dicotyledonous plant cell walls in the context of these elements. Not surprisingly, our analysis highlights many major gaps in our knowledge. However, the application of genomics, molecular genetics, and new analytical methods should provide many opportunities to close some gaps in the foreseeable future.

\section{Design Principles}

The body plan of a higher plant is essentially like a building made of "osmotic bricks." Each cell is osmotically pressurized to between 0.1 and $3.0 \mathrm{MPa}(1 \mathrm{MPa} \sim 145$ pounds per square inch). The pressure rigidifies the cells by creating tension in the cell walls. Each cell is glued to adjacent cells by pectic polysaccharides that normally prevent sliding of the cells under large strains. However, cell walls are also capable of controlled modifications that allow cells to expand in a polarized fashion during growth. Because each cell wall is attached to adjoining cell walls, coordinated expansion is necessary. It has been proposed that the role of the brassinosteroid hormones is to coordinate cell expansion (9).

Plant cell division involves the biogenesis and integration of new walls at the plane of division. In this process, two opposing walls form within the mother cell, and then the new walls integrate with the existing wall, and the plasma membrane repositions to form the daughter cells $(10,11)$. Certain cell types, such as the fiber cells in wood, are subject to mechanical stress and undergo additional cell wall synthesis after the cells have finished dividing and are fully expanded. This "secondary cell wall" is deposited interior to the "primary cell wall." Thus, the fundamental design principles include strength, expandability, and modularity.
Cell walls also provide a barrier to infection by pathogens. Exogenous application of cell wall fragments to uninfected plants triggers defensive reactions, indicating the existence of glycan-activated signal transduction chains. It has been proposed that some of the structural complexity in plant cell wall composition reflects the presence of latent signal molecules, which trigger defensive responses when they are released during the cell wall degradation that accompanies pathogenesis (12). Several lines of evidence have also implicated cell wall polysaccharide fragments and proteoglycans in developmental processes (13-15). For example, deglycosylation inactivated a proteoglycan named xylogen that mediates intercellular interactions required for xylem differentiation in cultured Zinnia cells (14). Thus, the design principles of cell walls cannot be understood solely in the context of mechanical properties.

\section{System Structure}

When viewed by electron microscopy (EM) (Fig. 1), cell walls appear to be a network of extended polysaccharides with high molecular weights $(16,17)$. In higher plants, the visually dominant structural features are cellulose microfibrils with diameters of $\sim 3 \mathrm{~nm}$, which appear to wrap around the cells and are cross-linked by single-chain polysaccharides such as xyloglucans.

Structural analysis of cell wall polysaccharides has resulted in the compilation of "average" structures for the major cell wall polysaccharides $(4,18)$. These are illustrated in figs. S1 to S6. In brief, the leaf cell walls of a dicot species such as Arabidopsis contain three major classes of polysaccharides: cellulose, hemicelluloses, and pectins. Cellulose is present as long unbranched fibrils composed of approximately 30 to 36 hydrogen-bonded chains of $\beta-1,4$-glucose. The length of the fibrils is unknown but single glucans containing up to 14,000 glucose units have been observed, corresponding to a fibril length of about $7 \mu \mathrm{m}$. Hemicelluloses are branched polysaccharides containing backbones of neutral sugars that can form hydrogen bonds to the surface of cellulose fibrils. Pectins are defined by the presence of uronic acids as 
major components. The simplest of these is homogalacturonan (HG), an unbranched polymer of $(1 \rightarrow 4) \alpha$-D-galacturonic acid. Rhamnogalacturonan I (RGI) has a backbone composed of alternating $(1 \rightarrow 2) \alpha$-L-rhamnose- $(1 \rightarrow 4) \alpha$ D-galacturonic acid decorated primarily with arabinan and galactan side chains. It has recently been suggested that RGI functions as a scaffold to which other pectins, such as rhamnogalacturonan II (RGII) and HG, are covalently attached as side chains (18).

A representative structure for an Arabidopsis leaf primary cell wall that is broadly consistent with more specialized models (18) and with views from EM $(16,17)$ is presented in Fig. 2. The complexity of the image underscores the challenge associated with understanding the structure, function, and synthesis of plant cell walls. The cellulose microfibrils, which are made at the plasma membrane, are insoluble because the glucan chains aggregate laterally by means of hydrogen bonding and van der Walls forces to produce crystalline structures of parallel chains. The other polymers are secreted as soluble polymers that must unfold and diffuse within the aqueous environment of the wall to their final destination. Because some of the polymers are insoluble when extracted from the wall, we speculate that they may be modified after secretion by the removal of structural components (e.g., branches) that facilitate solubility. Also, it has been proposed that some polymers are assembled into larger (less soluble) polysaccharides following secretion into the wall (19). One of the driving forces for assembly of the overall structure is thought to be the hydrogen bonding of hemicellulose to the surface of cellulose microfibrils (Fig. 2). Somewhat counterintuitively, biophysical studies have indicated that the presence of the hemicellulose cross-links weakens the mechanical strength of cell walls by preventing cellulose aggregation, thereby facilitating cell wall expansion (20).

The factors involved in pectin deposition are unknown. Pectins have been proposed to

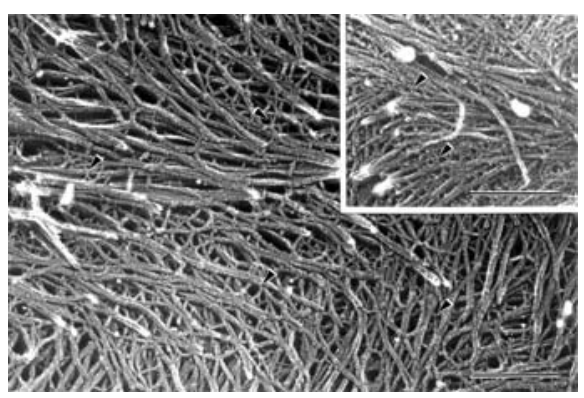

Fig. 1. Electron micrograph of outer cell walls of EDTA-extracted epidermal cells of pea (Pisum sativum) plants. Cellulose microfibrils and their cross-links are indicated by arrowheads. The inset shows the walls before extraction. Scale bars, $200 \mathrm{~nm}$. [Image from (16)] be important for control of wall porosity, for adhesion of adjoining cells (21), and in controlling the ionic environment of the cell wall (1). Additionally, analyses of mutations that alter the structure of RGII indicate that borate-diester cross-links between apiose residues in RGII molecules are also important for strengthening of the wall, intercellular adherence, and normal growth in vascular plants (22). Because the borate diester forms spontaneously, it provides a mechanism for forming cross-links after the polymers are assembled in place. Another example of in muro modification is the formation of calcium bridges between the carboxyl groups of HG chains to create interpolymeric adhesion. HG is thought to be made as a fully methylesterified polymer in the Golgi (4). Pectin methylesterases in the cell wall remove methyl groups, thereby making the carboxyls available to coordinate calcium ions that form interchain salt bridges. The existence of 67 genes for putative pectin methylesterases in Arabidopsis highlights the importance of this mechanism.

Measurements of the total sugar composition of cell walls from different tissues of Arabidopsis revealed that every tissue type has a different polysaccharide composition (23). Immunohistochemical studies with
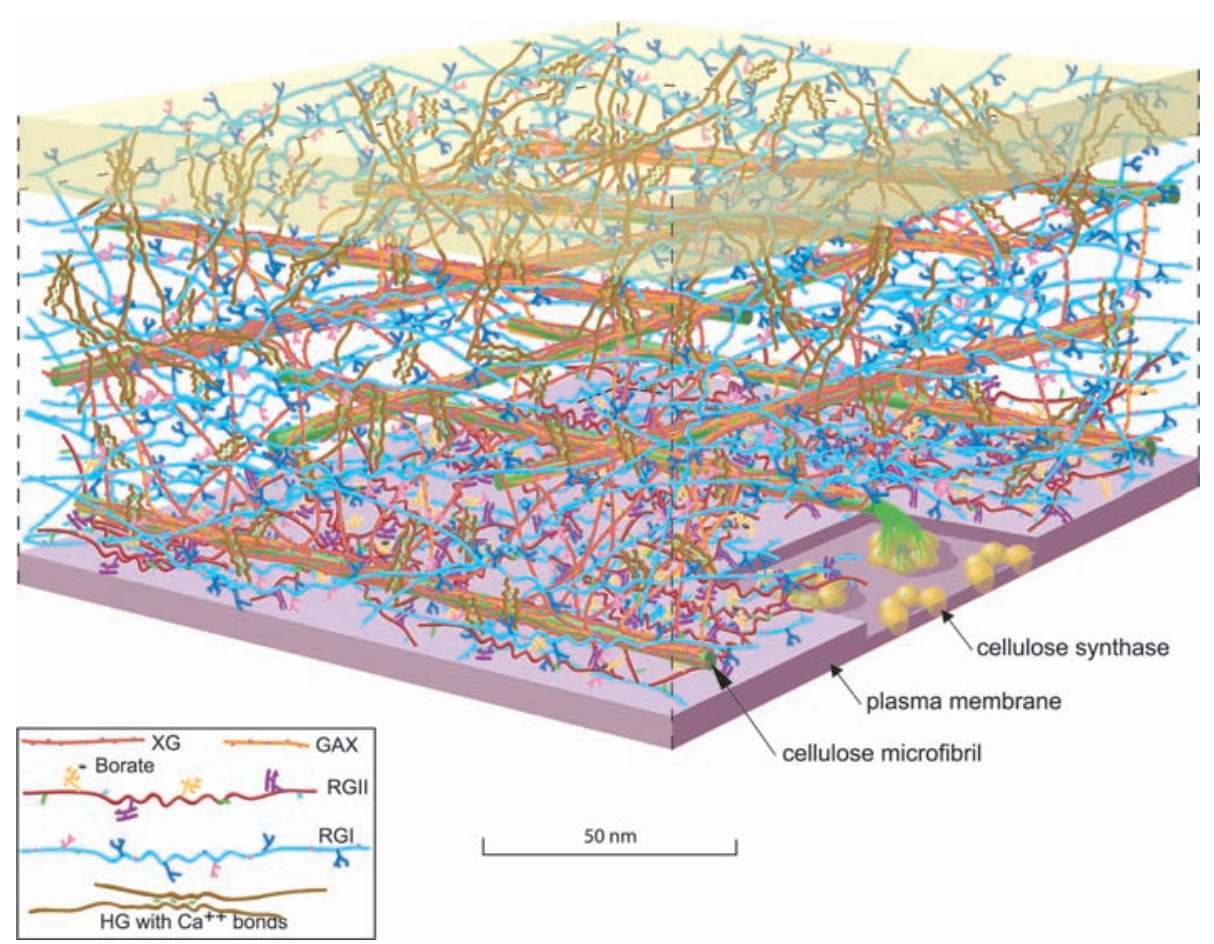

Fig. 2. Scale model of the polysaccharides in an Arabidopsis leaf cell. The amount of the various polymers is shown based approximately on their ratio to the amount of cellulose. The amount of cellulose shown was reduced, relative to a living cell (Fig. 1), for clarity. Because of the exaggerated distance between microfibrils, the hemicellulose cross-links [shown in dark orange (xyloglucan, XG) or light orange (glucoronoarabinoxylan, GAX)] are abnormally extended. Also, recent solidstate NMR studies have suggested that, in some plants, only about $8 \%$ of the surface of the cellulose microfibrils is occluded by XG (89). The figure is an elaboration of a model originally presented by McCann and Roberts (90). The figure was rendered by Abbey Ryan. monoclonal antibodies that recognize polysaccharide epitopes provide examples of spatial and temporal differentiation of wall polysaccharides $(24,25)$. These and other studies relation to growth and development $(24,26)$. Immunological studies have also shown that the various polymers are not uniformly distributed within the walls. RGII, for example, membrane (27), whereas polysaccharides such
mem to be enriched near the plasma as $\mathrm{HG}$ are enriched in the middle lamella, where adjoining cell walls abut. The differences between various cell types in cell wall composition and structure could reflect different needs for elasticity, the mobility of various types of molecules in the cell wall, or poise

respect to pathogen signaling.

The observation that each cell type may lematic to interpret experimental results on the basis of analyses of organs composed of different cell types. The use of isolated Zinnia cells, which can be forced to undergo synchronized terminal differentiation to vassystem wall biology $(28,29)$. Additionally, the large size and layered organization of cambium in tightly controlled in different cell types and in 
poplar trees facilitates sampling of steadystate mRNA levels in specific cell types at various stages of development by cutting thin sections with a cryomicrotome. Analysis of the mRNA on DNA chips and microarrays allowed a system-level analysis of secondary wall formation (30). The recent completion of the poplar genome sequence, and the fact that poplar and Arabidopsis have a similar complement of genes, will greatly facilitate the value of this experimental system.

\section{Control, Synthesis, and Assembly}

Remarkably little is known about the enzymes that catalyze synthesis of cell wall polysaccharides. Cellulose and callose ( $\beta$-1,3-glucan) are the only polysaccharides for which proteins involved in the synthesis of the main chains are known. In higher plants, cellulose synthase forms a "rosette" complex in the plasma membrane (31). The complex is one of the largest protein complexes known, with a diameter about equal to that of a ribosome. It is thought that each of the six subunits that comprise a rosette contains five or six CESA proteins, each of which synthesizes one of the $\beta$-1,4-glycans that comprise a microfibril in typical higher plants (Fig. 2). In some organisms, such as the red alga Erythrocladia subintegra, rectangular complexes of up to $230 \mathrm{~nm}$ in length produce ribbons of cellulose rather than fibrils (32).

Arabidopsis has ten cellulose synthase (CESA) genes, three of which are required for primary wall synthesis and at least three of which are required for secondary wall synthesis. It now appears from mutant analysis that the various genes are not functionally redundant; three different CESA proteins must be simultaneously present to produce a functional cellulose synthase (33). It has been hypothesized that this could be due to the geometric constraints associated with assembling 30 to 36 subunits into a planar, membrane-localized complex of approximately 3 million daltons (34).

Genetic screens for mutants of Arabidopsis deficient in cellulose have implicated a number of factors other than the CESA proteins. The KORRIGAN gene encodes a membrane-localized cellulose (35-37). Bacterial cellulose synthesis also requires a cellulase for in vivo activity but not for in vitro activity, suggesting a role in cellular processes rather than catalysis. As in plants, bacterial cellulose synthase is a membrane complex containing 12 to 25 subunits (38). However, bacteria use cellulose not in their walls but rather to create biofilms and adherence. The Arabidopsis COBRA gene encodes a glycophosphatidyl inositol (GPI)anchored protein of unknown function (39). Similarly, the KOBITO gene encodes a membrane protein of unknown function (40). The ectopic deposition of lignin in pith (elp) mu- tant is defective in a protein with sequence similarity to endochitinases (41). Because higher plants do not synthesize chitin, the ELP protein presumably hydolyzes another polysaccharide. Mutants deficient in glycosidase I and II, enzymes that catalyze the early steps of N-linked glycan maturation, are severely deficient in cellulose $(42,43)$. Unfortunately, in the absence of a robust and facile in vitro assay for cellulose synthase activity in Arabidopsis, it has not yet been possible to assign specific roles to these gene products.

It is notoriously difficult to convincingly measure cellulose synthase activity in extracts from higher plants. One of the challenges is the presence in plant membrane preparations of a highly active $\beta$-1,3-glucan synthase that obscures $\beta$-1,4-glucan synthase activity, necessitating detailed structural analysis of the products of assays. However, several groups have observed activity and have made progress toward defining improved assay conditions $(44,45)$. No exogenous primer was required to initiate synthesis of cellulose in vitro, raising doubts about the proposed involvement of sterol- $\beta$-glucoside as a primer (46). However, the discrepancy between in vivo and in vitro requirements for a cellulase in bacterial cellulose synthesis highlights the notion that in vitro conditions may not accurately reflect the in vivo conditions. Similarly, immunohistochemical evidence consistent with the idea that sucrose synthase may channel uridine 5 -diphosphate (UDP)-glucose to cellulose synthase (47) may be challenging to test in vitro.

Several CESA genes appear to be expressed throughout plants (34), even though cellulose synthesis is thought to be largely confined to expanding cells. This raises the possibility that cellulose synthesis is controlled posttranscriptionally. Bacteria, such as Escherichia coli, also exhibit constitutive expression of cellulase synthase (38). Enzyme activity is thought to be regulated by small effector molecules [i.e., cyclic diguanosine 5'-monophosphate (GMP)] or through stabilization of the complex by additional proteins (38). Cyclic di-GMP has not been observed in plants, and Arabidopsis does not have an obvious homolog of the enzyme that makes cyclic di-GMP.

A second level of control is responsible for the oriented deposition of cellulose fibrils. Cellulose fibrils are generally deposited perpendicular to the axis of elongation restricting lateral swelling and allowing longitudinal expansion. A variety of correlative evidence suggests that the orientation of cellulose deposition is, in some way, regulated by the orientation of microtubules. More than 40 years ago, cells treated with colchicine were observed to display random orientation of cellulose fibrils (48). Consist- ent with this, the fragile fiber mutants encoding a kinesin-like protein (fral) and a katanin-like protein ( $f r a 2$ ) have been demonstrated to have abnormal orientation of cellulose deposition $(49,50)$. However, studies of the conditional morl mutant of Arabidopsis, which is deficient in microtubule polymerization at the nonpermissive temperature, have shown that ordered cellulose deposition is possible in the absence of assembled cortical microtubules and an existing cellulose template $(51,52)$. It has also been observed that treatment of protoplasts with the cellulose synthase inhibitor isoxaben prevents characteristic orientation of the microtubules demonstrating cell wallto-cytoskeleton feedback (53). We believe that these seemingly contradictory lines of evidence may reflect a variable relationship between the cytoskeleton and the cellulose synthase complexes, depending on the stage of cell wall synthesis and expansion. Recent progress in visualizing microtubules in live cells (54), combined with new tools for simultaneously visualizing cellulose synthase, may clarify this relationship.

Most noncellulosic polysaccharides are thought to be synthesized in the Golgi, secreted, and covalently linked in muro into larger polysaccharides (19). The majority of the synthetic enzymes are integral membrane proteins, most of which have been intractable to purification. Genes for pectin synthesis have been particularly challenging to identify. However, mutant screens for variation in cell wall sugar composition (55) or for mutants with phenotypes indicative of defective cell walls $(56,57)$ have identified candidate genes for several of the enzymes involved. A tobacco mutant, defective in a putative glucuronyltransferase, has altered pectin content and defective intercellular attachment that appears to be due to a defect in RGII synthesis (58). The quasimodo mutant of Arabidopsis has reduced pectin because of a defect in a family 8 processive glycosyltransferase, which is a candidate for an $\mathrm{HG}$ synthase (59). Similar to most genes for enzymes implicated in cell wall synthesis in Arabidopsis, quasimodo is a member of a large family of related genes. A surprising finding was the discovery that a mutation in one of four isoforms of UDP-D-glucose 4epimerase, an enzyme that acts in the formation of UDP-D-galactose, affected the synthesis of proteoglycans and polysaccharides but not galactolipids (60). This and several related observations have been interpreted as supporting the concept that substrate channeling may be a broadly important control point in polysaccharide biosynthesis (61).

There have also been important breakthroughs in the identification of enzymes involved in the synthesis of xyloglucan. An $\alpha-1,2$-fucosyltransferase that adds the termi- 
nal sugar to a branch in the xygloglucan repeating unit was identified by purifying a protease-solubilized active fragment of the enzyme (62). The gene was subsequently found to complement the mur2 mutant of Arabidopsis, which was identified by a direct screen for altered cell wall sugar composition (63). Similarly, the gene for a xyloglucan galactosyltransferase was identified by sequence similarity to a galactosyltransferase purified from fenugreek (64). This gene was found to correspond to the mur3 mutant of Arabidopsis (65). Thus, substantial progress has been made by the application of both genetic and biochemical methods. Each of the cloned genes is represented in the Arabidopsis genome by a large number of related genes, and knowledge of the function of the founding member of a gene family will presumably greatly facilitate the subsequent assignment of function to the other members.

In principle, it should be possible to use reverse genetics methods to test the importance of candidate genes for cell wall functions. Arabidopsis has 29 cellulose synthase-like (CSL) genes with significant sequence similarity to cellulose synthase. Although mutations in several of the CSL genes have phenotypes, such as defective root hairs (66), resistance to bacterial attachment (67), or embryo lethality (68), it has not been possible to establish a primary biochemical defect in these or in mutants obtained by reverse genetics (23). A recent breakthrough in assigning function to these genes was the discovery that a CSL gene from guar catalyzed the accumulation of a $\beta$ linked mannan when expressed in transgenic soybean cells (69). In view of the problems associated with gene redundancy and potential lethality in pursuing a mutant approach to cell wall dissection, perhaps this approach of interspecies gene assays will prove to be broadly useful.

\section{System Dynamics}

A major challenge in plant biology is to understand how plant cell walls are modified to allow expansion and division. The network of polymers that resists turgor under normal circumstances must be relaxed during cell expansion so that the cell increases in volume, usually in a directional way, which gives rise to morphological effects at the tissue level. As the cell expands, new polysaccharides must be synthesized and integrated into the wall to retain the appropriate mechanical and functional properties.

Two classes of proteins have been specifically implicated in wall expansion. Xyloglucan endotransglycosylase (XET) catalyzes the ability to "recombine" two molecules of xyloglucan by endotransglycosylations $(2,20)$. It is generally accepted that this activity allows controlled cell wall expansion by catalyzing transglycosylation of free xyloglucan with molecules bound to cellulose. In vivo activity has been elegantly demonstrated by infiltrating fluorescently labeled xyloglucan fragments into cell walls, where they become covalently integrated into larger xyloglucan molecules (70). Unfortunately, the large number of XET genes in Arabidopsis has prevented a compelling genetic test of the role of these enzymes (71).

Another intriguing class of proteins is the expansins, which were originally discovered on the basis of their ability to cause acidinduced extension of isolated walls (72). Expansins have weak sequence similarity to glucanases but have no detectable hydrolytic activity in enzyme assays. Evidence from in vitro assays (73) suggests that they disrupt noncovalent interactions between wall polymers. The large number of expansin genes in Arabidopsis has frustrated attempts to genetically test the role of these enzymes (74). Nonetheless, an important role for expansins was demonstrated by placing microspheres impregnated with an expansin near the apical meristems of tobacco or tomato plants $(75,76)$. This caused the formation of a leaf at a location that disrupted the normal phyllotaxy of the plant, presumably by inducing cell expansion at an abnormal location.

Analysis of the transcriptional control of cell wall composition is just beginning (30). The relatively small number of enzymes that have been characterized at both the gene and enzymatic level poses a considerable restriction in the interpretation of results obtained with genomic methods. However, there have been numerous observations suggesting that plants can sense and respond to the functional properties of cell walls. For instance, it has been observed that under conditions in which cellulose synthesis is blocked by mutation (42) or by chemical inhibitors (77), large amounts of pectin accumulate. In some tissues, inhibition of cellulose synthesis also leads to ethylene- and jasmonate-dependent lignin accumulation (78). Whole-genome transcript profiling of Arabidopsis cells habituated to isoxaben, a specific inhibitor of cellulose synthase, revealed that more than 900 genes were up-regulated and another 900 were down-regulated (79). Thus, it appears that plants have mechanisms for sensing and responding to changes in cell wall integrity and mechanical performance $(12,80)$. In this respect, the cell wall integrity system in yeast (81) may be a useful conceptual model for the mechanisms in plants.

The organization and composition of the yeast cell wall is so different from plant cell walls that it has not been used as a model for plants. However, because yeast cell walls perform functions similar to plant cell walls, they may use similar regulatory principles. It has been estimated that as many as 1200 genes affect cell wall structure and organization in Saccharomyces cerevisiae (82), suggesting a complex regulatory system. Several type I membrane proteins-Wsc1-4p, Mtl1p, and Mid2p-have been implicated as sensors of cell wall integrity $(81,83)$. These proteins may sense changes in membrane stretching (84) and transduce signals by means of a guanine nucleotide exchange factor that activates the SLT2p/Mpk1p mitogen-activated protein kinase (MAPK) pathway by means of protein kinase $C$ activation of a MAPK kinase kinase. No obvious homologs of the yeast sensor proteins have been found in plants $(80)$, but there are large numbers of potential alternatives, such as wall-associated kinases and leucinerich receptors, that are under investigation.

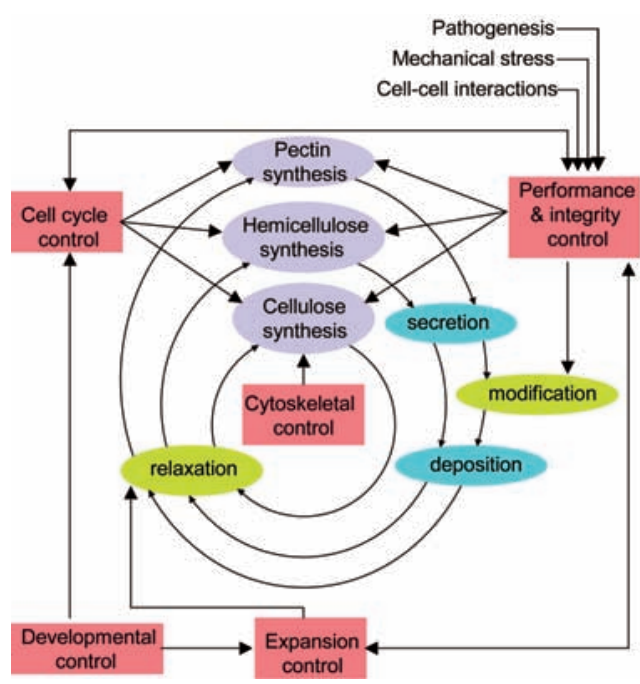

Fig. 3. A simplified system diagram for a primary cell wall. Synthesis and modification of polysaccharides are shown in purple and green, respectively. Cell biological processes are shown in blue and regulatory processes are shown in red. The diagram highlights the fact that wall synthesis is dynamic and cyclical. Genetic evidence suggests that cellulose provides a framework on which other polysaccharides (i.e., hemicellulose) assemble (91), presumably based simply on binding coefficients. Thus the cycle of cellulose synthesis lies at the heart of wall biogenesis. The factors that control pectin deposition are obscure but are assumed to be biophysical factors such as solubility, diffusion coefficients, and binding constants-all of which can be modified by minor changes to pectin structure such as the presence or absence of methyl-esterification or Oacetylation. Post-secretory modification of pectin (e.g., demethylation and borate-ester formation) provide mechanisms for modifying wall functionality without synthesis. The most notable feature of the diagram is the large number of inputs into a control process that we have termed "performance and integrity control." The existence of this unknown control process is inferred from responses to inhibitors, pathogens, and mutations. 


\section{R E V I E W}

\section{Perspectives and Future Directions}

A highly simplified system diagram incorporating the major concepts discussed here is presented in Fig. 3. The cyclical nature of the diagram emphasizes that the expansion of the cell wall and the integration of a new cell plate during cytokinesis are components of the cell cycle. Thus, we infer that many of the genes involved in primary cell wall synthesis and modification will be found to be controlled by factors that control other aspects of the cell cycle. However, cells that are programmed to continue dividing would be expected to have different controls than cells that are terminally differentiated. Each differentiated cell type probably has a different combination of controls to ensure that composition of the wall is compatible with the needs of that cell type. Although not emphasized here, cell walls can be modified in response to environmental stimuli. Thus, the two main inputs are developmental and environmental processes. Indeed, because cell size and cell shape are functions of cell wall expansion, any attempt to understand the mechanics of morphogenesis will ultimately lead to questions about the control of cell wall synthesis and expansion. We speculate that as methods for interrogation of cell wall structure and function improve, large numbers of morphologically abnormal mutants that cannot currently be understood in a developmental context will be found to lie at the interface of morphogenesis, the cell cycle, and cell wall biogenesis.

Viewing cell walls in a developmental context may help explain the large numbers of structurally similar genes for cell wallrelated enzymes that are evident in the sequenced plant genomes. It is apparent that for some functions, such as cellulose synthesis, a small number of genes are used in most or all of the roughly 40 cell types in a plant. This is compatible with speculation that cellulose synthesis is not primarily controlled at the transcriptional level. By contrast, the large numbers of structurally related genes in other gene families may suggest that other cell wall-related processes are based on the participation of specialized genes in a tissue or temporal dependent manner. It is also likely that, because polysaccharides are composed of a small number of sugars but a relatively large number of different linkages, the members of large families of structurally similar genes encode enzymes that exhibit linkageor context-dependent differences in catalysis.

The development of methods for determining where and when each gene is expressed in Arabidopsis and other plants (85) is a high priority in moving toward a more refined understanding of how walls are controlled. The power of transcript profiling with DNA chips or arrays to associate genes with processes cannot be fully realized as long as
RNA samples are derived from mixtures of cell types. Hypotheses concerning gene function derived from transcript profiling can be rapidly tested by exploiting the extensive collection of indexed insertion mutations in $\mathrm{Ara}-$ bidopsis (86). At present, sequence-indexed insertions are available for approximately 22,600 of the genes in Arabidopsis (87).

Although powerful genomic resources are available in Arabidopsis $(86,88)$, they are only a subset of the diverse resources that will be required to permit formulation of a detailed system model of cell walls. The development of tools, such as additional monoclonal antibodies or aptamers, differentiated cell cultures of Arabidopsis, diagnostic hydrolytic enzymes for structural analysis, and substrates for enzyme assays, are needed. These tools will facilitate analysis of mutants and will help to elucidate the function of enzymes, individual polysaccharides, and structural motifs that occur in the walls of Arabidopsis and other species. New biophysical methods that permit improved imaging and nanoscale interrogation or manipulation of cell walls may also facilitate a deeper understanding of how the components are organized and how that organization results in the observed physical properties. Looking over the horizon, hypothetical methods such as scanning probe nuclear magnetic resonance (NMR) or confocal EM would be very useful for visualizing the fine structure of cell walls.

Finally, the emphasis here on Arabidopsis should not obscure the substantial diversity in wall composition between plant species. For instance, in commelinoid monocots, most of the neutral hemicellulose and pectins are replaced by glucuronoarabinoxylan. As experimental methods and resources for studying complex polysaccharides and nanocomposites improve, this diversity will provide a rich source of information about structure-function relationships.

\section{References and Notes}

1. N. C. Carpita, D. M. Gibeaut, Plant J. 3, 1 (1993).

2. S. C. Fry, New Phytol. 161, 641 (2004).

3. M. C. McCann et al., Phytochemistry 57, 811 (2001).

4. B. L. Ridley, M. A. O'Neill, D. A. Mohnen, Phytochemistry 57, 929 (2001).

5. B. Henrissat, P. M. Coutinho, G. J. Davies, Plant Mol. Biol. 47, 55 (2001)

6. S. Rhee, E. Osborne, P. Poindexter, C. Somerville, Plant Physiol. 133, 1170 (2003).

7. J. Vogel, T. Raab, C. Schiff, S. Somerville, Plant Cell 14, 2095 (2002)

8. H. Kitano, Science 295, 1662 (2002)

9. Z. Y. Wang, J. X. He, Trends Plant Sci. 9,91 (2004)

10. U. Mayer, G. Jürgens, Curr. Opin. Plant Biol. 7, 599 (2004).

11. S. Cutler, D. Ehrhardt, Proc. Natl. Acad. Sci. U.S.A. 99, 2812 (2002)

12. S. Vorwerk, S. C. Somerville, C. R. Somerville, Trends Plant Sci. 9, 203 (2004).

13. J. C. Dumville, S. C. Fry, Plant Physiol. Biochem. 38, $125(2000)$

14. H. Motose, M. Sugiyama, H. Fukuda, Nature 429, 873 (2004).

15. Q. Hall, M. C. Cannon, Plant Cell 14, 1161 (2002).

16. T. Fujino, Y. Sone, Y. Mitsuishi, T. Itoh, Plant Cell Physiol. 41, 486 (2000)
17. M. C. McCann, B. Wells, K. Roberts, J. Cell Sci. 96, 323 (1990).

18. J.-P. Vincken et al., Plant Physiol. 132, 1781 (2003).

19. E. M. Kerr, S. C. Fry, Planta 217, 327 (2003).

20. E. Chanliaud, J. De Silva, B. Strongitharm, G. H. Jeronimdis, M. J. Gidley, Plant J. 38, 27 (2004).

21. M. C. Jarvis, S. P. H. Briggs, J. P. Knox, Plant Cell Environ. 26, 977 (2003).

22. M. A. O'Neill, T. Ishii, P. Albersheim, Annu. Rev. Plant Biol. 55, 109 (2004).

23. T. Richmond, C. Somerville, Plant Mol. Biol. 47, 131 (2001).

24. G. Freshour et al., Plant Physiol. 131, 1602 (2003).

25. W. Willats, L. McCartney, W. Mackie, J. Knox, Plant Mol. Biol. 47, 9 (2001)

26. J. P. Knox, P. J. Linstead, J. King, C. Cooper, K. Roberts, Planta 181, 512 (1990).

27. M. N. V. Williams, G. Freshour, A. G. Darvill, P. Albersheim, M. G. Hahn, Plant Cell 8, 673 (1996).

28. D. Milioni, P. E. Sado, N. J. Stacey, K. Roberts, M. C. McCann, Plant Cell 14, 2813 (2002).

29. T. Demura et al., Proc. Natl. Acad. Sci. U.S.A. 99, 15794 (2002).

30. J. Schrader et al., Plant Cell 16, 2278 (2004).

31. S. Kimura et al., Plant Cell 11, 2075 (1999).

32. I. Tsekos, K. Okuda, R. M. Brown Jr., Protoplasma 193, 33 (1996).

33. N. Taylor, R. Howells, A. Huttly, K. Vickers, S. Turner, Proc. Natl. Acad. Sci. U.S.A. 100, 1450 (2003).

34. W. R. Scheible, R. Eshed, T. Richmond, D. Delmer, C. Somerville, Proc. Natl. Acad. Sci. U.S.A. 98, 10079 (2001).

35. F. Nicol et al., EMBO J. 17, 5563 (1998).

36. I. His, A. Driouich, F. Nicol, A. Jauneau, H. Höfte, Planta 212, 348 (2001).

37. S. Sato et al., Plant Cell Physiol. 42, 251 (2001)

38. U. Römling, Res. Microbiol. 153, 205 (2002).

39. G. Schindelman et al., Genes Dev. 15, 1115 (2001).

40. S. Pagant et al., Plant Cell 14, 2001 (2002).

41. R. Q. Zhong, S. J. Kays, B. P. Schroeder, Z. H. Ye, Plant Cell 14, 165 (2002).

42. C. S. Gillmor et al., J. Cell Biol. 156, 1003 (2002).

43. J. E. Burn et al., Plant J. 32, 949 (2002).

44. J. Lai-Kee-Him et al., J. Biol. Chem. 277, 36931 (2002)

45. K. Okuda, L. Li, K. Kudlicka, S. Kuga, R. M. Brown Jr., Plant Physiol. 101, 1131 (1993).

46. L. C. Peng, Y. Kawagoe, P. Hogan, D. Delmer, Science 295, 147 (2002)

47. V. V. Salnikov, M. J. Grimson, D. P. Delmer, C. H. Haigler Phytochemistry 57, 823 (2001).

48. P. B. Green, Science 138, 1404 (1962)

49. D. Burk, Z. Ye, Plant Cell 14, 2145 (2002).

50. R. Q. Zhong, D. H. Burk, W. H. Morrison, Z. H. Ye, Plant Cell 14, 3101 (2002).

51. R. Himmelspach, R. E. Williamson, G. O. Wasteneys, Plant J. 36, 565 (2003)

52. K. Sugimoto, R. Himmelspach, R. E. Williamson, G. O. Wasteneys, Plant Cell 15, 1414 (2003).

53. D. D. Fisher, R. J. Cyr, Plant Physiol. 116, 1043 (1998).

54. S. L. Shaw, R. Kamyar, D. W. Ehrhardt, Science 300 $1715(2003)$

55. W. Reiter, C. Chapple, C. Somerville, Plant J. 12, 335 (1997).

56. M. Fagard, H. Höfte, S. Vernhettes, Plant Physiol. Biochem. 38, 15 (2000).

57. R. E. Williamson, J. E. Burn, C. H. Hocart, Cell. Mol. Life Sci. 58, 1475 (2001).

58. H. Iwai, N. Masaoka, T. Ishii, S. Satoh, Proc. Natl. Acad. Sci. U.S.A. 99, 16319 (2002).

59. S. Bouton et al., Plant Cell 14, 2577 (2002)

60. G. J. Seifert, C. Barber, B. Wells, L. Dolan, K. Roberts, Curr. Biol. 12, 1840 (2002)

61. G. J. Seifert, Curr. Opin. Plant Biol. 7, 277 (2004).

62. R. Perrin et al., Science 284, 1976 (1999).

63. G. Vanzin et al., Proc. Natl. Acad. Sci. U.S.A. 99, 3340 (2002)

64. M. E. Edwards et al., Plant J. 19, 691 (1999).

65. M. Madson et al., Plant Cell 15, 1662 (2003).

66. B. Favery et al., Genes Dev. 15, 79 (2001).

67. Y. Zhu et al., Plant Physiol. 132, 494 (2003)

68. F. Goubet et al., Plant Physiol. 131, 547 (2003).

69. K. S. Dhugga et al., Science 303, 363 (2004).

70. K. Vissenberg, V. Van Sandt, S. C. Fry, J. P. Verbelen, J. Exp. Bot. 54, 335 (2003).

71. K. Nishitani, J. Plant Res. 115, 303 (2002). 
72. S. McQueen-Mason, D. J. Cosgrove, Proc. Natl. Acad. Sci. U.S.A. 91, 6574 (1994).

73. S. E. C. Whitney, M. J. Gidley, S. J. McQueen-Mason, Plant J. 22, 327 (2000)

74. Y. Li, L. Jones, S. McQueen-Mason, Curr. Opin. Plant Biol. 6, 603 (2003).

75. S. Pien, J. Wyrzykowska, S. McQueen-Mason, C. Smart, A. Fleming, Proc. Natl. Acad. Sci. U.S.A. 98, 11812 (2001).

76. A. J. Fleming, S. McQueen-Mason, T. Mandel, C. Kuhlemeier, Science 276, 1415 (1997).

77. E. Shedletzky, M. Shmuel, T. Trainin, S. Kalman, D. Delmer, Plant Physiol. 100, 120 (1992).

78. A. Cano-Delgado, S. Penfield, C. Smith, M. Catley, M. Bevan, Plant J. 34, 351 (2003).

79. I. Manfield et al., Plant J. 40, 260 (2004).

80. E. Pilling, H. Höfte, Curr. Opin. Plant Biol. 6, 611 (2003).

81. R. Garcia et al., J. Biol. Chem. 279, 15183 (2004).
82. P. W. J. de Groot et al., Comp. Funct. Genomics 2 124 (2001).

83. B. Philip, D. E. Levin, Mol. Cell. Biol. 21, 271 (2001).

84. G. Smits, J. Kapteyn, H. van den Ende, F. Klis, Curr. Opin. Microbiol. 2, 348 (1999).

85. K. Birnbaum et al., Science 302, 1956 (2003)

86. J. Alonso et al., Science 301, 653 (2003).

87. Information about the number of sequence-indexed insertions can be found at The Arabidopsis Information Resource (TAIR): http://arabidopsis.org/news/monthly/ TAIR_News_Sept04.jsp.

88. J. C. Redman, B. J. Haas, G. Tanimoto, C. D. Town Plant J. 38, 545 (2004)

89. T. J. Bootten, P. J. Harris, L. D. Melton, R. H. Newman, J. Exp. Bot. 55, 571 (2004).

90. M. McCann, K. Roberts, in The Cytoskeletal Basis of Plant Growth and Form, C. W. Lloyd, Ed. (Academic Press, London, 1991), pp. 109-130.
91. S. Turner, C. Somerville, Plant Cell 9, 689 (1997).

92. We thank K. Roberts for thoughtful suggestions. This work was supported by grants from the U.S. Department of Energy (DE-FG02-03ER20133) and the NSF (MCB 0114562). T.H. and S.V. were recipients of fellowships from the Deutche Forschungsgemeinschaft. S.P. was the recipient of a fellowship from the Carl Tryggers Foundation (CTS 03258). H.Y. was supported by a fellowship from the NIH Stanford Training Program in Genomics.

\section{Supporting Online Material}

www.sciencemag.org/cgi/content/full/306/5705/2206/

Figs. $\mathrm{S} 1$ to $\mathrm{S} 6$

10.1126/science. 1102765

\section{Science sets the pace}

online manuscript submission

\section{www.submit2science.org}

Science can now receive and review all manuscripts electronically

online letter submission

\section{www.letter2science.org}

Have your voice be heard immediately

\section{speed submission}




\section{Science}

\section{Toward a Systems Approach to Understanding Plant Cell Walls}

Chris Somerville, Stefan Bauer, Ginger Brininstool, Michelle Facette, Thorsten Hamann, Jennifer Milne, Erin Osborne, Alex Paredez, Staffan Persson, Ted Raab, Sonja Vorwerk, and Heather Youngs

Science, 306 (5705),

\section{View the article online}

https://www.science.org/doi/10.1126/science.1102765

Permissions

https://www.science.org/help/reprints-and-permissions

Use of think article is subject to the Terms of service

Science (ISSN 1095-9203) is published by the American Association for the Advancement of Science. 1200 New York Avenue NW, Washington, DC 20005. The title Science is a registered trademark of AAAS.

American Association for the Advancement of Science 